\title{
Smart distribution grid application with different storage elements
}

\author{
Reiner Johannes Schütt ${ }^{\mathrm{a}}$, Meike Oldekop ${ }^{\mathrm{b}}$ \\ ${ }^{a}$ West Coast University of Applied Sciences, 25746 Heide, Germany and \\ CE WindEnergy Center of Excellence for Wind Energy, 24943 Flensburg, Germany, \\ ${ }^{b}$ West Coast University of Applied Sciences, 25746 Heide, Germany
}

\begin{abstract}
On account of the profound change process in electric power generation, transmission and distribution a lot of activities are started to plan, to build up and to operate smart distribution grids. Experiences from laboratory test setups are well known, experiences from public used smart grids are actually published only a little. Therefore there are numerous questions how to adapt the smart grid characteristics to the special boundary conditions of a given grid region and which divergences must be considered between planning and operation. This paper describes some key experiences in planning, building up and operating a smart grid for the German isle of Pellworm. It takes into account the first lessons learned from the operation of this smart grid.
\end{abstract}

Keywords: Smart region, hybrid power plant, storage elements, flexible loads, adjustable transformer substation, energy management system, demand side management

\section{Introduction}

Caused by the attractive feed-in tariffs in Germany the number of wind power plants (WP), photovoltaic power plants (PVP) and biogas combined heat and power plants (BCHP) increased so rapidly, that the existing grid infrastructure leads to restrictions in the feed-in of these plants[1], [2]. There are regions where the produced energy of renewables is a multiple of the consumption in this area. One of these areas is the west coast in the north of Germany with an average wind speed in hub height of more than six to nine $\mathrm{m} / \mathrm{s}$. Especially, for these regions it is suggested to install energy storage systems to use the energy where it is produced. It is proposed to integrate storage elements, controllable loads and renewable power plants into a centralized energy management system (CEMS) to achieve the maximum relief of the grid infrastructure [3]-[5]. So in the past several smart grids are planned and build-up in these areas [6], [7] but there is only little information describing the differences between the calculated characteristics in the planning process and the results during operation.

For the German isle of Pellworm the main technical and non technical aspects in setting up a smart grid are well described [8], [9]. Pellworm, located on the west coast of Schleswig-Holstein, is the third biggest North Frisian Island with $38 \mathrm{~km}^{2}$. HalligHooge is also belonging to the island and is supplied by electrical grid from Pellworm. Pellworm is surrounded by a national park and the world heritage- natural site: The Wadden Sea. On the island live round about 1100 inhabitations, which are registered in 650 households. The economy is shaped through tourism with more than 200 beds and a high amount of agricultural enterprises. With a long-term average wind speed of $9 \mathrm{~m} / \mathrm{s}$ in $80 \mathrm{~m}$ height Pellworm is a favoured location for wind turbines (WT) whereof the largest part is organized in a civic wind farm.

There exists extensive data for the island, which concerns both, the energy situation of the island as a whole and the annual cycles of decentralized generators. The annually generated energy of round about

\footnotetext{
* Manuscript received July 10, 2014; revised July 27, 2014.

Corresponding author: Reiner Johannes Schütt; Tel.: +49 4818555 350; E-mail address: schuett@fh-westkueste.de.

doi: $10.12720 /$ sgce.4.1.15-21
} 
$21 \mathrm{GWh}$ from WT, photovoltaic systems (PVS) and one BCHP on the island is opposed to an annual consumer load of $7 \mathrm{GWh}$. Remarkable is the high amount of electrical storage heaters (EHS) as well as the high amount of electrical heat pumps. The isle is connected to the mainland with the help of two $20 \mathrm{kV}$ sea-cables which have a restricted apparent power of 14MVA and 11MVA. Without grid extensions it is not useful to install further WT on the isle. On the mainland there are a lot of documented time periods when the $20 \mathrm{kV}$ distribution grid and the $110 \mathrm{kV}$ transport grid are overloaded due to the massive feed in of installed wind power plants at the west coast. So for these time periods the WPP have to reduce their feed-in power. A smart grid installed in several regions could help to relieve the distribution and transport grid at the west coast.

Within the innovation study [8] it is proposed to introduce a smart grid on the isle of Pellworm step by step. After the specification of the elements for a core smart grid it should follow the construction and then the evaluation of the operation for this core smart grid. After the evaluation a full smart grid should be planned and build up.Meanwhile the core smart grid is built up and since September 2013 it is operating in different operation modes to evaluate the effectiveness. This paper describes the main characteristics of the installed smart grid and the first results.

\section{Fundamentals of Smart Grid Design for the Isle of Pellworm}

There are formulated several goals for the design of a smart grid Pellworm. They are formulated with the help of operational strategies as follows:

- Optimize the use of regionally based renewable sources (own consumption operation)

- Reduce the peak power at the connections to the mainland (peak shaving operation)

- Stabilize the voltage on the isle with active and reactive power control (local grid service operation)

- Trade at the day-ahead and intraday market or at the market for reserve power (trading operation)

- Optimize a combination of several goals (multifunctional operation)

For the design of the smart grid several restrictions have to be considered:

- Technical data of the main existing resources (cables, substations, WT, PVS, BCHP, loads)

- Availability, reliability and cost-effectiveness of additional resources (especially the storage elements, measuring and communication systems and the energy management system)

- Acceptance of planned actions produced energy of renewables

The first goal for the design is to maximize the own consumption of renewables only with the help of additional storage systems and with considering availability, reliability and cost-effectiveness.A change in the energy exchange between the island and the mainland has a significant impact on the stresses of the grid infrastructure on the mainland. The design of the storage elements takes into account the $15 \mathrm{~min}-$ values of all existing loads with the power profile $P_{L}(t)=p_{L}$ and of all existing generators with the power profile $P_{G}(t)=p_{G}$ for one year. For big loads, the measured values are used, for small loads like private households the standardized load profiles are used. For the WT, PV and BCHP and for the big loads the measured $15 \mathrm{~min}$-values are used. The residual power is defined as:

$$
p_{R}=p_{G}-p_{L}
$$

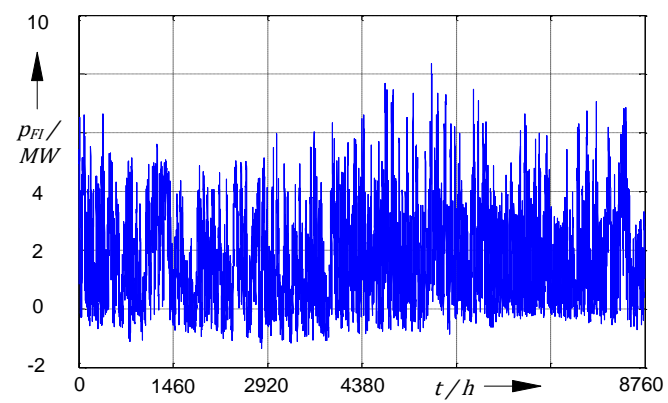

Fig. 1. Annual residual power profile for Pellworm. 
Fig. 1 shows the calculated curve of $p_{R}$ for one year, the annual residual power profile before the conversion to a smart grid. For Pellworm, most of the time $p_{R}$ is positive. For the mainland the residual power is feed in power $p_{F I}=p_{R}$. If $p_{F I}<0$, then the power is procured. The procured power $p_{P}$ is defined as:

$$
p_{P}=-p_{R} \text { for } p_{R}<0 \text { and } p_{P}=0 \text { for } p_{R}>0
$$

The annual energy procurement $W_{P a}$ using the fifteen-minutes average values $P_{P a v, 15 m}$ of $p_{P}$ can be calculated with $\Delta t=0,25 \mathrm{~h}$ as follows:

$$
W_{P a}=\int_{0}^{8760 h} p_{P} d t=\sum_{0}^{4.8760} P_{P a v, 15 m} \cdot \Delta t
$$

The annual residual power profile for Pellworm is indicated by a maximum of $P_{F I m a x}=8300 \mathrm{~kW}$, a minimum of $P_{\text {FImin }}=-P_{P M a x}=1300 \mathrm{~kW}$ and an annual energy procurement without additional storage elements of $W_{P a}=337 \mathrm{MWh}$. An indicator in the residual profile for the need and size of additional storage elements is the maximum procured energy $\Delta W_{P M A X}$ for a time period where no generated power occurs. This value can be calculated as the storage energy which has to be installed to prevent that the residual power is less than zero and if the storage elements is always charged when $p_{G}>p_{L}$. For the given residual power profile this value is calculated to $\Delta W_{P M A X}=13 \mathrm{MWh}[8]$.

\section{Aspects to the Choice of Storage Elements}

In [3], [10] and [11] selected aspects such as size, location and technology for storage elements in smart grids are described. For the isle of Pellworm a simplified holistic approach is chosen. The main characteristics of storage elements are the capacity or storable energy $W_{\max }$, the maximum charging and discharging power $P_{C \max }$ and $P_{D \max }$ and the used technology. The chosen technology determines a lot of characteristics like permissible depth of discharge, round trip efficiency, self discharge, own consumption, allowable time gradient of $p_{C}$ and $p_{D}$, number of allowed load cycles, lifetime and costs. The technology affects properties like investment and operation costs, volume, safety, availability and reliability.

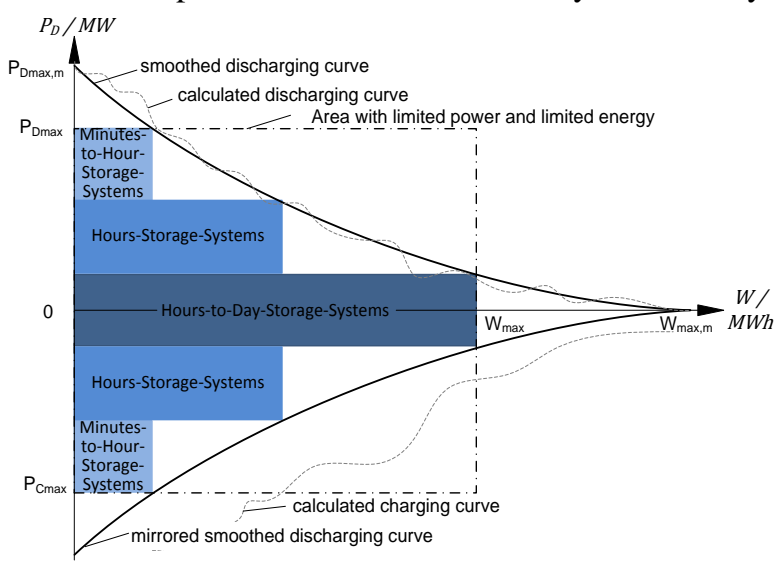

Fig. 2. Generalized storage curve of power as function of energy.

Fig. 2 shows the general performance of storage elements in the range of some MWh and some MW that means in the range of batteries in different technologies. Storage elements are divided in "hours-today-storage elements", "hours-storage-elements" and "minutes-to-hour-storage-elements" in different technologies. If the residual power profile is known, the needed charging and discharging powers as function of time can be calculated and can be transformed to a function power versus energy. For a given grid region, where the generated energy is bigger than the energy of the loads, the calculated discharging curve will be smoothed and the maximum values for $\mathrm{P}$ and $\mathrm{W}$ will be limited. The selected storage elements where placed into the area, so that they consider the smoothed discharging curve and the 
maximum values.

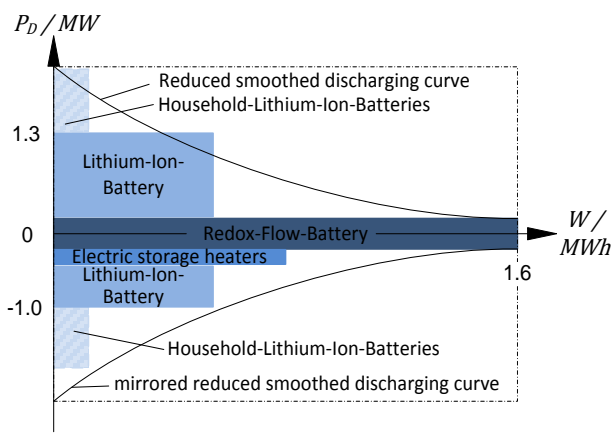

Fig. 3. Storage curve and storage elements for Pellworm.

Fig. 3 shows the application for the given residual load profile of Pellworm. Calculation shows, that the storage energy could be limited to $1600 \mathrm{kWh}$ to achieve a reduction of $W_{P a}$ of more than $90 \%$. Due to the efficiency of the storage systems, the power has to be limited up to $1600 \mathrm{~kW}$. To achieve the best approximation of the restricted area, a hybrid storage system consisting of a centrally located medium size Redox-Flow-Battery (CRFB) and a centrally located medium size Lithium-Ion-Battery (CLIB) is needed.

\section{Smart Grid Power System Infrastructure}

The choice of the storage size and technology is only one aspect in the design of the smart grid Pellworm. Fig. 4 shows the structure of the medium-voltage-grid and the position of the existing decentralised generators. From 2012 to 2013 this infrastructure was added by additional elements. With the help of the medium voltage grid scheme it can be checked whether the allowable voltage variations are exceeded.

At a central location (In de See) the existing hybrid power plant with a $300 \mathrm{~kW}-\mathrm{WT}$ and a $772 \mathrm{~kW}-\mathrm{PVS}$ at a central located area of E.ON-HanseWärme GmbH the additional CLIB and CRFB are installed, so that this area can be described as a "Tribrid-Power-Plant", that means photovoltaic, wind and storage. To prevent violations of the voltage at this node, two adjustable $20 \mathrm{kV} / 400 \mathrm{~V}$ transformer substations (ATS) are installed.

Six households with together 35 EHS were modified so that the EHS can be controlled. At the key nodes of the isle several automated substations (ASS) replaced the old ones. 205 smart meters in 160 private households are installed and the communication infrastructure was built up. In eleven households HLIB were installed which will be integrated into the central energy management system. Fig. 5 shows the central located "Tribrid Power Plant" with CLIB, CRFB, PVS, WT and local control and visitor center which is operating since September 2013.

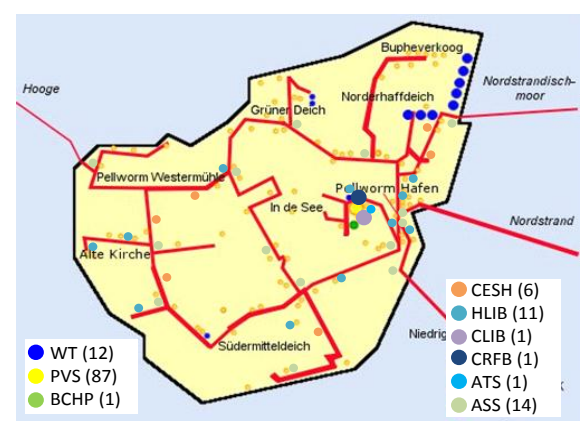

Fig. 4. Schematic MV-grid and key infrastructure elements after smart grid installations.

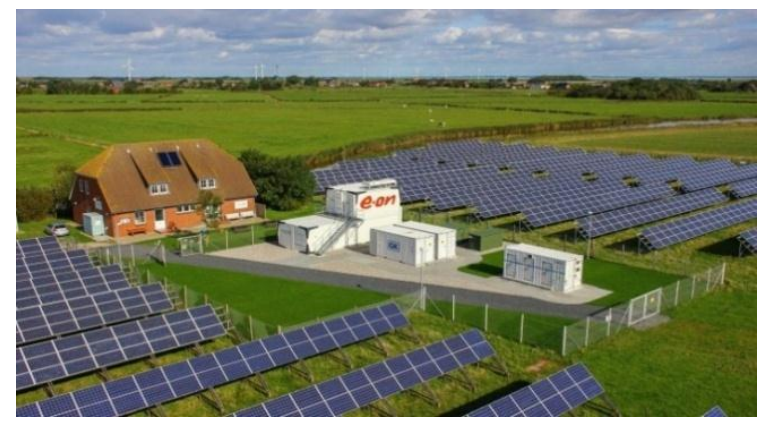

Fig. 5. Central "Tribrid Power Plant" with CLIB, CRFB, PVS, WT and local control center. 
Table 1 summarizes the key energy indicators for the isle. Calculations shows that the annual energy procured can be reduced form $\mathrm{W}_{\mathrm{Pa}}=337 \mathrm{MWh}$ down to some $10 \mathrm{MWh}$. Measures should show the differences between the calculated and real value.

Table 1.Key energy indicators for the isle of Pellworm (extension based on [8])

\begin{tabular}{|c|c|c|c|}
\hline Production & Amount & Installed Power & Yearly energy production \\
\hline Wind energy turbines (WT) & 12 & $5725 \mathrm{~kW}$ & $15251 \mathrm{MWh}$ \\
\hline Photovoltaic systems (PVS) & 87 & $2742 \mathrm{~kW}$ & 2586MWh \\
\hline Biogas combined heat power plant (BCHP) & 1 & $530 \mathrm{~kW}$ & 4453MWh \\
\hline Total production & 100 & $8997 \mathrm{~kW}$ & $22290 \mathrm{MWh}$ \\
\hline Consumption & Amount & Installed Power & Yearly energy consumption \\
\hline Household customers & 731 & & 3274MWh \\
\hline Electric heating systems (EHS) & 148 & $630 \mathrm{~kW}_{\mathrm{el}}$ & 815MWh \\
\hline Others & 297 & & 2979MWh \\
\hline Total consumption & 1156 & & $7068 \mathrm{MWh}$ \\
\hline Procurement without storage systems & & Power & Energy \\
\hline Annual value & & $38 \mathrm{~kW}$ (average) & 337MWh \\
\hline Maximum value & & $1300 \mathrm{~kW}$ (peak) & $13 \mathrm{MWh}\left(\Delta \mathrm{W}_{\mathrm{Pmax}}\right.$, see advice $)$ \\
\hline Storage Elements & Amount & Charging/Discharging Power & Installed Energy Capacity \\
\hline Central Redox-Flow-Battery (CRFB) & 1 & $200 \mathrm{~kW}_{\mathrm{C}} / 200 \mathrm{~kW}_{\mathrm{D}}$ & $1600 \mathrm{kWh}$ \\
\hline Central Lithium-Ion-Battery (CLIB) & 1 & $560 \mathrm{~kW}_{\mathrm{C}} / 1100 \mathrm{~kW}_{\mathrm{D}}$ & $560 \mathrm{kWh}$ \\
\hline Household-Lithium-Ion-Batteries (HLIB) & 11 & $80 \mathrm{~kW}_{\mathrm{C}} / 80 \mathrm{~kW}_{\mathrm{D}}$ & $79 \mathrm{kWh}$ \\
\hline (Controllable EHS) & 39 & $(194 \mathrm{~kW})$ & (780kWh, only charging) \\
\hline Total storage key parameters & 48 & $974 \mathrm{~kW}_{\mathrm{C}} / 1380 \mathrm{~kW}_{\mathrm{D}}$ & 2239kWh (3204kWh charging.) \\
\hline
\end{tabular}

\section{Smart Grid Automation Infrastructure}

SCADA, grid control or grid management systems (GMS) for the distribution grids are well known, even decentralized energy management systems for small distribution grids are described [12], [13]. To achieve a significant reduction of the transportation and the distribution grid in highly penetrated regions a central grid management system is necessary. Here the information has to be collected to ensure the grid security and availability. The central energy management system (CEMS) receives the data from the GMS. It calculates the control signals for the storage elements and the controllable loads due to the actual values and the reference values. The reference values consider the operation mode and additional information like weather forecast and energy stock exchange information. The control signals are exchanged with the GMS who sends the information to the components. This way ensures, that the EMS is not influencing the grid security and that the two management systems are working in a mismatch.

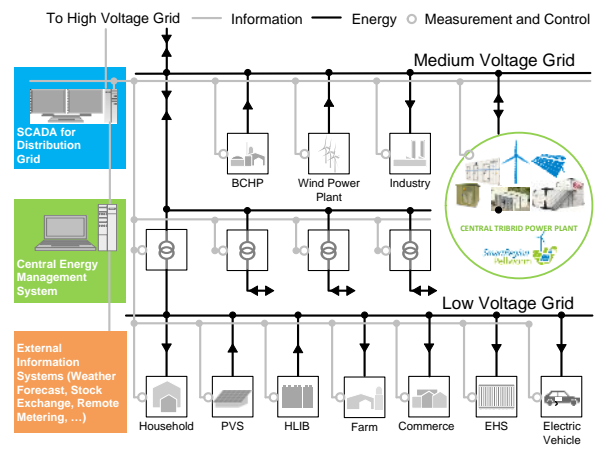

Fig. 6. Power grid and automation infrastructure for the isle of Pellworm.

Fig. 6 shows the power grid and automation infrastructure installed on the island and in the locations, where the energy management units are. For the energy management the automation infrastructure of Pellworm has to be exceeded. Besides the CEMS it mainly includes:

- Automatic local grid stations,

- Smart meters with advanced meter management and integrated load control functionality in particular for the usage of decentralized controllable loads in the low voltage grid, 
- Communication interfaces between the storage elements and the CEHS and the GMS,

- Rapid, highly voluminous data communications with households and communication to external information systems like weather forecast and energy stock exchange

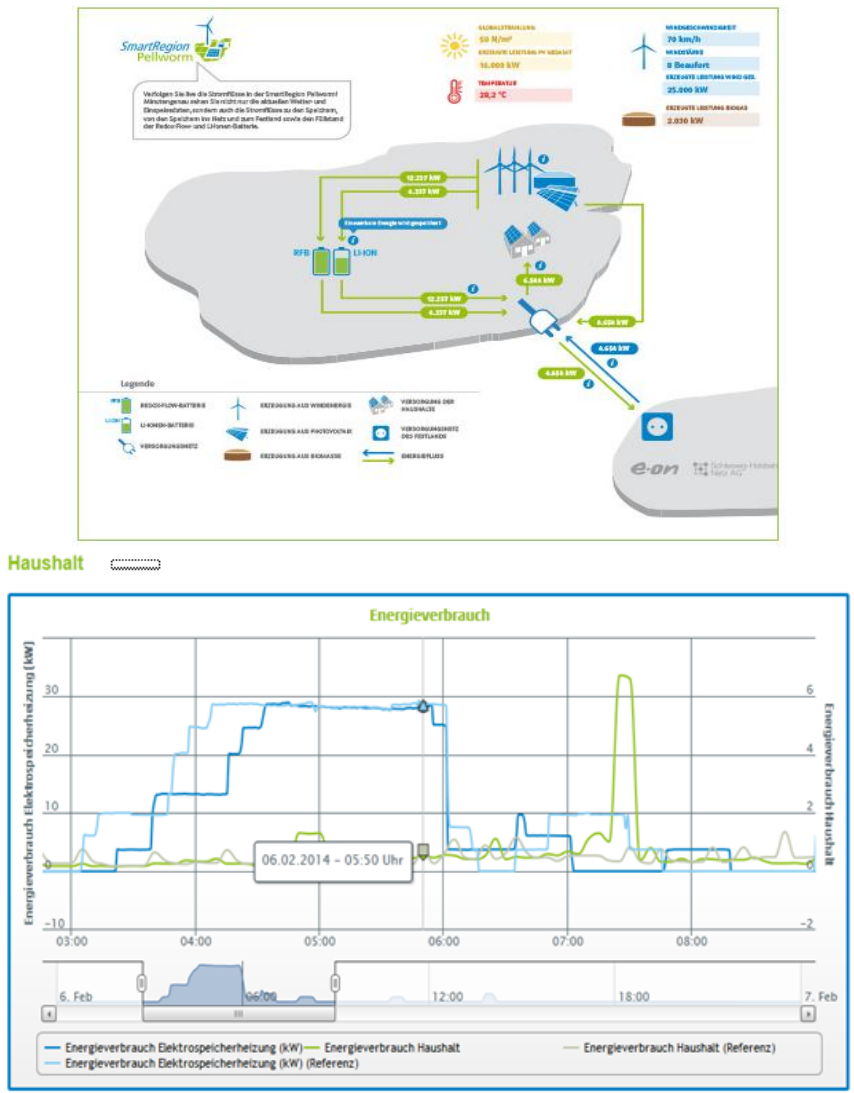

Fig. 7. SmartRegion Homepage with online power measurement [14] and App for private households [15]

Fig. 7 shows the SmartRegionPellworm homepage where characteristic values like charging and discharging power and the state of charge of CLIB and CRFB are shown. Besides this the actual power values of the WT and the PVS at the Tribrid-Power-Plant and the BCHP together with some weather datas are shown [14].To improve the acceptance of the started works on Pellworm, the private households, who have installed a smart meter, a HLIB or a CEHS can use a SmartRegion App [15]. With the help of this app shown in Fig. 7 the customer can see whether his own energy portfolio and can see the power and energy time courses. This app enables the user to control his own energy procurement or his own energy feed-in if he has a PVS.

\section{Conclusion}

The isle of Pellworm is marked by a yearly production of renewables which is three times higher than the consumption of the island. This is a typical relation of many regions with a big percentage of installed WT and PVS. The paper shows how to plan and to build up a smart grid in a given region. Some general aspects and some applied aspects for the isle of Pellworm are discussed. It is shown that a hybrid solution of storage elements leads to an effective solution to reduce the procurement from the overlayed transport grid. For the isle of Pellworm the transport grid is located on the mainland. The use of the procured power profile shows, that it is not useful to achieve a $100 \%$-self-sufficiency with the help of battery storage elements cause the needed energy is too big to achieve a cost-effective solution.

The paper shows the needed additional infrastructure and the structure of a central energy management 
system which uses the collected data of the grid control system. So on Pellworm there is the needed grid and automation infrastructure to operate a smart grid for a limited region. For the operating period several operation modes are named. The operation modes can be called as business models and operation strategies too. In the next twelve months the own consumption operation mode, the local grid service operation mode, the energy trading operation mode and a multifunctional operation mode will be evaluated.

The experiences will then be integrated into a further specification of a full smart grid. Quantitative declarations about emerging costs for the construction and operation of a smart grid in connection with the grid load can be made. This enables the smart grid Pellworm to clarify key issues for the future energy supply. In particular, it could show that in areas with a substantial surplus production of renewable energy the operation of a Smart Grid with appropriate storages could relieve the electrical grid significantly.

\section{Acknowledgements}

The research leading to these results is part of the project SmartRegionPellworm. It is funded by the German Federal Ministry for the Environment, Nature Conservation Building and Nuclear Safety as a lighthouse project in the German Energy Storage Initiative. The project analyses and demonstrates the smart grid operation and evaluates economic and ecological evaluations in a field test. The key elements of the project are carried out by the following partners from industry and academia: E.ON Hanse AG (consortia leader), West Coast University of Applied Sciences (FachhochschuleWestküste), FraunhoferAnwendungszentrumfürSystemtechnik (IOSB-AST), Fraunhofer-Institutfür Umwelt-, Sicherheits- und Energietechnik (UMSICHT), Gustav Klein GmbH \& Co. KG, Institut für Hochspannungstechnik RWTH Aachen, Saft Batterien GmbH, Schleswig-Holstein Netz AG

\section{References}

[1] Bruns E, Ohlhorst D. Wind Power Generation in Germany.The Journal of Transdisciplinary Environmental Studies vol. 10, no. 1, 2011.

[2] Hallberg P Active Distribution System Management - A key tool for the smooth integration of distributed generation. Eurelectric Report, Bruxelles, 2013.

[3] Gantz J, Amin M. Optimal Mix and placement of energy storage systems in power distribution networks for reduced outage costs. In: Proc. IEEE Proceedings of Energy Conversion Congress and Exposition, 2012.

[4] Momoh J. Smart Grid - Fundamentals of Design and Analysis. New York: Wiley IEEE Press, 2012.

[5] Haesen E, Multi-objective optimization of the integration of stochastic distributed energy resources in electricity grids. Leuven: $\mathrm{PhD}$ dissertation, K.U. Leuven, 2009.

[6] Giordano V, Gangale F,Fulli G,Jiménez M, Onyeji I. Smart Grid projects in Europe: Lessons learned and current developments. European Commisiion JRC Scientific and Policy Reports, Netherlands, 2012.

[7] Karg L. Smart Energy Made in Germany - Zwischenergebnisse der E-Energy-Modellprojekte auf dem Weg zum Internet der Energie.B.A.U.M. Consult GmbH, München/Berlin, 2012.

[8] Schütt R, Nicolai S. Innovationsstudie Pellworm: Zukünftige elektrische energieversorgung der Insel Pellworm.West Coast University of Applied Sciences, Heide, 2011.

[9] Schütt R, Oldekop M. Future energy supply for the Isle of Pellworm. International Journal of Smart Grid and Clean Energy, vol. 2, No. 3 October 2013.

[10] Yu DBV. Novel methodology to determine the optimal energy storage location in a microgrid and address power quality and stability. Eaton Powering Business worldwide, Ireland and Cleveland, Ohio, USA, May 2014.

[11] Koopmann S, Scheufen MSA. Integration of stationary and temporary storage systems inot multi-stage expansion planning of active distribution grids. In: Proc. IEEE PES Innovative Smart Grid Technologies Europe Conference, Istanbul, 2013.

[12] Gönen T. Electric Power Distribution Engineering. Boca Raton, Florida: CRC Press Taylor \& Francis Group, 2014.

[13] Chakrabortty A, Ilić MD. Control and Optimization Methods for Electric Smart Grids. Series: Power Electronics and Power Systems, Vol. 3, Springer Verlag, 2012.

[14] E. On Hanse AG, Schleswig-Holstein Netz AG. http://www.smartregion-pellworm.de/home.html. E.on Hanse AG, Schleswig-Holstein Netz AG. [Online]. [Zugriff am 1007 2014].

[15] Schleswig-Holstein Netz AG and E.ON-Hanse AG. Energiemanager-App for private households. Rendsburg: Schleswig-Holstein Netz AG and E.ON-Hanse AG, 2014. 